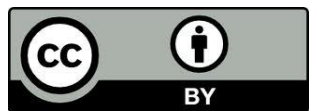

\title{
A mulher no contexto histórico contemporâneo de Edith Stein ${ }^{1}$
}

\author{
The woman in the contemporary historical context of Edith Stein
}

Clélia Peretti

Doutorado em Teologia. Membro da Academia Internacional de Teologia Prática (IAPT). Professora Adjunta do Programa de Pós-Graduação e Bacharelado em Teologia da PUCPR cpkperetti@gmail.com.

RESUMO: Este artigo aprofunda as contribuições de Edith Stein (1891-1942), filósofa contemporânea e discípula de Edmund Husserl (1859-1938) que seguindo a via traçada por seu mestre, com seu método fenomenológico, aponta para a "essência das coisas" e propõe uma antropologia filosófica do ser humano. Discute-se no decorrer do trabalho sob a ótica do pensamento de Edith Stein, os significado ontológicos de natureza e essência da mulher, a forma feminina de abordagem das questões relacionadas com o "mundo-da-vida" e o papel da mulher na "comunidade". Enfatiza-se, a posição de Edith Stein diante dos movimentos feministas e pedagógicos, sua inserção nos movimentos culturais e sociais, sua relevância na escola fenomenológica e originalidade no uso do método fenomenológico no estudo da pessoa humana em suas variadas dimensões. Destaca-se também sua capacidade de transitar nas diversas áreas do saber, sua reflexão sobre a condição da mulher na problemática da intersubjetividade na perspectiva éticosocial e jurídico-política. O esforço de Edith Stein com seus estudos, conferências e sua inserção nos movimentos feministas consiste em mostrar o papel fundamental da mulher nos vários segmentos da sociedade e, além disso, nos mais variados campos profissionais. Suas ideias apresentam-se como revolucionárias para a época, pois o espaço da mulher era o privado e não o público, faltando-lhe o pleno direito de inserção na sociedade. Edith Stein, diversamente dos movimentos feministas que reivindicavam os direitos de inserção na sociedade, afirma que nenhuma solução é possível para o problema da mulher se antes não se repensa o papel do homem também, ou seja, se antes não se analisam as características peculiares dos dois sexos. Trata-se, portanto, de analisar a perspectiva fenomenológica de Edith Stein no estudo do ser humano como um sujeito masculino/feminino, situando-nos assim no interior dos estudos de gênero que nasceram com o intuito de analisar, sobretudo a dimensão feminina.

Palavras-chave: Edith Stein; Mulher; Movimentos feministas; Masculino / feminino;

Ontologia e antropologia do ser humano.

\footnotetext{
${ }^{1} \mathrm{O}$ conteúdo deste artigo se encontra em parte na minha tese de doutorado (PERETTI, CLÉLIA. Edith Stein e as questões de gênero: perspectiva fenomenológica e teológica. Clélia Peretti; orientadora Valburga Schmiedt Streck; co-orientadora Angela Ales Bello. São Leopoldo: EST/PPG, 2009, 302 f.)
} 
ABSTRACT: This article deepens the contributions of Edith Stein (1891-1942), contemporary philosopher and disciple of Edmund Husserl (1859-1938) that followed the path outlined by his master, his phenomenological method, points to the " essence of things " and proposes a philosophical anthropology of the human being. It is argued in this work from the perspective of the thought of Edith Stein , the ontological meaning of nature and essence of the woman, the feminine form of addressing issues related to the " life -world " and the role of women in " community ". It emphasizes the position of Edith Stein before the feminist and pedagogical movements, their inclusion in the cultural and social movements, their relevance in the phenomenological school and originality in the use of the phenomenological method in the study of the human person in its various dimensions. Also noteworthy is his ability to move in various areas of knowledge, its reflection on the status of women in the problem of intersubjectivity in socio-ethical and legal- political perspective. The effort of Edith Stein with his studies, conferences and its insertion in the feminist movement is to show the key role of women in the various segments of society and, moreover, in various professional fields . His ideas are presented as revolutionary for the time, because the woman space was private and not the public, lacking the full right to inclusion in society . Edith Stein , unlike the feminist movements that claimed the rights to reintegrate into society, said that no solution is possible for the woman's problem is not before rethinks the role of man also , that is, if not before analyzing the peculiar characteristics of two sexes . It is, therefore, to examine the phenomenological perspective of Edith Stein in the study of the human being as a male / female subject, placing us well within gender studies who were born in order to analyze, especially the feminine dimension .

Keywords : Edith Stein; Woman; Feminist movements; Male / female; Ontology and anthropology of the human being. 


\section{Introdução}

A irrupção do pensamento feminino se apresenta como uma resposta aos desafios contemporâneos. É significativo encontrar no pensamento de João Paulo II uma terminologia semelhante quando afirma que o emergir do "gênio feminino" é urgente diante dos desafios do nosso tempo, necessitado de ternura e carregado de tensões. O pensamento feminino vem se apresentando como um dos possíveis caminhos para o hodierno pluralismo filosófico e cultural. Há situações hoje, em que lideranças femininas cresceram de forma mais sólida, vinculadas a representações como as mulheres no movimento negro, nas lutas sindicais, nas representações parlamentares, nas situações de governabilidade e representando vários segmentos sociais e religiosos.

O pensamento feminino, nas suas máximas expressões, tem sua origem no final do século XIX e início do século XX, quando se discutem questões relacionadas à mulher e ao seu comportamento, seja na literatura como em quaisquer segmentos sociais. Trata-se de um "pensamento pensado por mulheres" que fazem do ser mulher o ponto de partida de sua experiência prática e teorética. É uma reflexão que se orienta para a produção intelectual de mulheres centralizadas em questões ontológicometafísicas.

A pesquisa científica muito tem contribuído para mostrar a contribuição das mulheres na história do pensamento ocidental e, ao mesmo tempo, na reconstrução de sua própria história. Da antiguidade até nossos dias, muito do que foi estruturado sobre a vida e o pensamento das mulheres foi realizado por homens cuja imagem da mulher é, muitas vezes, um reflexo seu. Sempre que se discutiam questões relacionadas à mulher e ao seu comportamento, era comum vê-la tratada como objeto de dominação masculina, relegada à submissão e à inferioridade perante o poder do homem. $\mathrm{O}$ valor do ser humano era pré-determinado a partir do lugar social, sua cor e seu sexo. E, nessa escala de valores, as mulheres quase sempre foram consideradas antropológica e socialmente inferiores.

Passa-se, gradativamente de uma história de mulheres vítimas a uma história de mulheres ativas e comprometidas consigo mesmas e com a sociedade. A historiografia muito tem contribuído para compreender os problemas enfrentados pelas mulheres e suas conquistas. A influência direta ou indireta do feminismo como um discurso 
intelectual, filosófico e político, dos movimentos e teorias feministas, na vida das mulheres aparece como um fenômeno cultural significativo. As mulheres vão adquirindo maior consciência de sua ação no mundo do trabalho, na educação e na produção científica.

Assim, a participação da mulher na formação sócio-educativa, cultural, política e religiosa leva questionar sobre o significado de "ser mulher", ligado aos contextos históricos. Lutas, transformações, fortalecimentos marcam a vida das mulheres há muito tempo, e várias foram às tentativas de integração de sua humanidade no espaço público. Dentre elas destaca-se a valorização da sua história, quando mergulhadas em silêncios impostos e sufocadas por imagens distorcidas decidem escrever sua própria história, ou seja, tornar visível o invisível.

No século XVIII, ainda se discutia se as mulheres eram seres humanos como os homens ou se estavam mais próximas dos animais irracionais. Nos século XIX, as mulheres vêem reconhecido o direito à educação, assim no século $\mathrm{XX}$, descobriu-se que as mulheres têm uma história, podendo com a ajuda dos movimentos e das reivindicações feministas, ser contada (PERROT, 2007, p. 11).

O itinerário percorrido pelas mulheres no desenvolvimento de suas histórias acompanha em surdina o "movimento" das mulheres em direção à emancipação e à liberdade. Dá-se uma passagem gradual de uma história de mulheres vítimas para chegar à história das mulheres ativas, comprometidas com elas mesmas e com a sociedade. A história das mulheres transformou-se, hoje, em história de gênero, que insiste não somente no resgate dos papéis, na valorização do corpo (sexo, maternidade e submissão), e da alma, mas também nas relações entre sexos e na integração das masculinidades.

É importante salientar que a reconstrução da história das mulheres, desde a Antiguidade até os nossos dias, reflete uma imagem de mulher construída pelos homens. O desenvolvimento de um pensamento feminino veio influenciar o "pensar feminino" no mundo contemporâneo. Todavia, a história do pensamento oriental e ocidental sobre o feminismo nos atesta que as mulheres sempre tiveram que lutar, com exceção de alguns casos, contra uma realidade a elas hostil, submetidas a funções ou situações subalternas, tanto nas atividades culturais quanto técnicas (ALES BELLO; PEZZELLA, 2005, p. 5). Subsiste, ainda hoje, uma diferença de gênero, uma 
diversidade entre o "ser homem" e o "ser mulher" que deixa transparecer modalidades diferentes de sentir, de perceber, de ver, de pensar e de projetar o mundo. Essa modalidade se deve a relação configurada entre os sexos no ocidente que, por sua vez, traduz-se num pensamento filosófico que nega a possibilidade de "um sujeito mulher" e de tudo o que está próximo à vida, ao concreto porque considerado secundário, não digno de ser investigado.

Certamente existiram na história, correntes filosóficas ou ambientes culturais que abriram espaços também para as mulheres, mas em geral tratou-se sempre de escolas ou de seitas religiosas, como por exemplo, a escola Pitagórica ou a escola de Alexandria, porque mais próximas a uma exigência de verdade que não era aquela abstrata ou universal expressa pelo pensamento (ALES BELLO; PEZZELLA, 2005, p. $6)$.

Uma diferente abordagem sobre a vida, sobre o pensamento feminino, nasce a partir de uma diversidade antropológica que não é somente de caráter físico, mas é, sobretudo, espiritual. O ser humano é considerado nesta perspectiva como uma unidade psicofísica e espiritual, por isso também a diferença física tem influências sobre o aspecto espiritual, do contrário, estaríamos diante de seres humanos divididos entre corpo e espírito, o que não corresponde à experiência que fazemos de nós mesmos e dos outros.

Um exemplo emblemático de figuras que souberam harmonizar questões filosóficas, antropológicas e teológicas, com a filosofia e a vida foi Edith Stein (PEZZELLA, 2003, p. 5). Ao lado dela, estão outras figuras femininas que atuaram no contexto da época, já mencionadas neste trabalho tais como Simone Weil, Hannah Arendt, Maria Zambrano, Hedwig Conrad-Martius que se destacaram pelo cuidado com às "questões emergenciais do tempo, ligadas à vida e à experiência pessoal" 2 . Não poderíamos deixar lembrar também figuras brasileiras como Adélia Prado, Cecília Meirelles e Ivone Gebara, dentre outras que, além de tomarem consciência do seu "ser mulher”, deixaram sua contribuição intelectual e suas marcas na história.

Particular ênfase será dada a posição de Edith Stein perante a situação da mulher. Seus escritos são fruto de reflexões e debates com líderes do movimento

\footnotetext{
${ }^{2}$ A singularidade dessas figuras femininas é que elas mantinham sempre uma relação com a vida e a experiência pessoal e também com o contexto histórico no qual estavam inseridas. Particularmente significativa é a atenção que direcionam à sociedade, à vida política e ao desenvolvimento das ciências de sua contemporaneidade (ALES BELLO, 2003, p. 7).
} 
católico alemão entre as duas guerras mundiais. Ela se posiciona a partir de uma nova lógica antropológica. O feminino, que até então era visto, por muitos, como sexo frágil, em suas análises fenomenológicas faz emergir a essência e o ethos da feminilidade, a dignidade e vocação da mulher.

Edith Stein participa dos movimentos feministas e intelectuais de sua época. Motiva as jovens em formação a se consientizarem de que elas também são capazes de "pensar", e de "fazer filosofia". Se empenha-se, como enfermeira voluntária em serviços de assistência aos soldados, na cura dos feridos nos hospitais auxiliares da Cruz Vermelha durante o período da primeira Guerra Mundial e, ainda, na ajuda aos pobres. De certa forma, a guerra contribui para a constituição de uma experiência de responsabilidade, sobretudo, com a valorização do trabalho feminino a serviço da pátria e para a abertura de novas possibilidades profissionais. Como educadora, luta pela formação feminina e participa nas lutas pelas reformas educativas.

Nos anos 1920-1940, Edith Stein, e muitas mulheres, embora ainda não reconhecidas academicamente, se empenharam para o resgate do valor da feminilidade em vista de uma tomada de posição social e política. Mas, a questão da igualdade entre homens e mulheres, a igualdade de gênero, sobretudo, em relação aos direitos, tem sido uma longa luta, intensificada pelos movimentos feministas da década 1960-1970 em muitas partes do mundo.

Verifica-se, entretanto, uma forte resistência às mudanças antropológicas, culturais e sociais, em outros termos, resistências em relação à comprensão da identidade feminina. Não obstante isso, o fenômeno da inserção das mulheres, cada vez mais consistente no mundo da cultura e, em particular, na especulação filosófica e no mundo do trabalho, sobretudo no século XX, tem possibilitado respostas expressivas sobre o ser humano.

As pesquisas sobre a questão feminina foram se multiplicando de modo diversificado e se enriquecendo com contribuições significativas nos últimos anos. Amplia-se, nessa ótica também, o feminismo cristão que busca dar à mulher uma nova consciência de si mesma e conduz, contemporaneamente, ao emergir das teologias de libertação e a elaboração de uma teologia feminista.

\section{Olhando a mulher com olhos de mulher: bases da formação feminina}


O interesse de Edith Stein para com "os problemas da educação da mulher" foi determinado pelos acontecimentos históricos da época. $\mathrm{Na}$ Conferência sobre "Problemas de formação feminina", escreve: "o objetivo que envolveu o entendimento da natureza feminina foi determinado pelo ponto de vista ideológico-religioso e pelas considerações de ordem econômica" (STEIN, 1999, p. 174). Enquanto mulher e filósofa questiona-se e se empenha em primeira pessoa para demostrar suas capacidades no âmbito social e, sobretudo, intelectual.

A maioria de seus ensaios sobre a mulher se situa entre sua conversão e a entrada no Carmelo, ou seja, entre os anos 1922 a 1933. Seus escritos cristalizam sua experiência de ensino em sala de aula e como oradora, revelam sua capacidade excepcional de empatia na formação das mulheres em todas as esferas da vida, assim como traços característicos de uma personalidade que a identificam como uma educadora inata e intelectual incansável.

Como professora, Edith Stein se vê confrontada com a questão da educação de meninas e moças, e como docente universitária enfrenta a tarefa de formar mulheres. [...] investiga a essência e a missão da mulher, para assim estabecer diretrizes seguras de teoria e prática da educação feminina (GELBER, 1999, p. 17).

É atenta à situação espiritual da mulher com relação aos grandes problemas do seu tempo, em particular com o matrimônio, a maternidade, a profissão, a vida do povo, a política mundial e ao problema da eternidade. Acreditava na necessidade de uma educação que contribuísse para conscientizar a mulher de sua identidade, dignidade e de seu valor, assim como de sua missão e da esperança que dela derivava para a Alemanha e para o mundo. Compreendia a importância e o alcance da formação feminina para a inserção da mulher como agente de transformação social e de mudança cultural.

A crescente presença feminina no mundo do trabalho trazia no seu bojo a questão das relações sociais e de gênero, do diálogo entre as ciências sociais e a teologia e de corresponsabilidade no processo de desenvolvimento. A motivação básica para essas questões está na utopia de transformação da realidade, na perspectiva ética de construção do humano e de libertação, realidade essa entendida na sua dimensão sociocultural, socioeconômica, política e teológica. Dizia: "a penetração das mulheres nos diversos setores profissionais pode vir a ser um benefício para toda a vida social, 
tanto particular quanto pública, desde que se resgate justamente o aspecto específico da ética feminina" (STEIN, 1999, p. 63).

Sua atividade pedagógica baseia-se na concepção de uma educação harmoniosa, na fundamentação religiosa da ação educadora e no caráter especial da formação feminina. Edith Stein projeta uma formação abrangente e equilibrada de todas as forças físicas e psíquicas naturais da mulher. Insiste, na formação da mulher como mulher, na sua genuína identificação com sua verdadeira natureza, com seu caráter eminentemente feminino.

A formação feminina cristã deve tornar a mulher capaz de cumprir seus deveres em sentido natural e sobrenatural. O respeito pela alteridade feminina é a condição para se entender o verdadeiro significado da igualdade entre a mulher e o homem. Não é a igualdade que anula as diferenças entre os sexos, ou considera o masculino como protótipo do humano. Ao contrário, Edtih Stein reconhece a igualdade indispensável para a reciprocidade entre mulheres e homens, e fundamenta esta sua tese na interpretação da ordem divina da criação e da redenção.

A humanidade deve ser entendida como um único grande indivíduo. (A história da salvação só faz sentido sob essa condição). Cada pessoa humana possui seu lugar e sua tarefa no desenvolvimento da história e, nesse processo evolutivo, acontece também a realização plena da espécie homem e mulher (STEIN, 1999, p. 208).

Disso resulta o interesse da filósofa de aprofundar o significado da natureza e da essência da mulher, considerando sempre a relação entre os gêneros. Essa é uma exigência que leva analisar tanto a natureza feminina quanto a natureza masculina, não só para identificar suas características próprias, mas também sua complementaridade. A mulher não é apenas diferente do homem, mas distinta dele. Ela tem de descobrir sua maneira peculiar de ser. "Toda mulher tem aptidões e dons individuais que a faz aspirar por uma vocação especial, além da feminina em geral” (STEIN, 1999, p. 138-139).

Rejeita as teses das feministas sobre a diferença entre homens e mulheres socialmente determinadas e propõe, assim, um trabalho de formação feminina, convicta de que se desdobra em espécie feminina e masculina de modo que é na estrutura do ser humano que se manifesta sua essência e seus traços específicos. A autora afirma que: 
alma difere a relação entre o espírito e a sensitividade bem como a relação entre as diversas forças espirituais. À espécie feminina corresponde a unidade e a integridade de toda a personalidade psicofísica, o desenvolvimento harmonioso das forças; a espécie masculina se destaca pela potencialização máxima de forças isoladas (STEIN, 1999, p. 2006).

A diferenciação da espécie, tanto no sentido da virilidade quanto da feminilidade, manifesta-se de maneira diversa nos indivíduos, em realizações mais ou menos perfeitas da espécie, e desenvolvem este ou aquele traço. Em cada indivíduo, encontramos o elemento feminino e o elemento masculino, sendo que apenas um deles predomina. No ser humano, há um diferente ritmo constitutivo dos indivíduos, mas que o investem em toda sua estrutura de corpo, alma e espírito. Daí, portanto, a necessidade de um trabalho formativo que abranja a totalidade do ser humano. Todo esforço formativo humano tem a missão de contribuir para a reintegração da natureza humana. Tanto o homem quanto a mulher são vítimas da degeneração causada pelo pecado original. Cabe, portanto, ao educador o trabalho de contribuir na correção das várias degenerações (corpórea, sensual e espiritual) e para a manifestação completa da natureza e missão da mulher. "O homem e a mulher tem a missão de dar forma à imagem de Deus que carregam dentro de si” (STEIN, 1999, p. 207).

Do ponto de vista teológico, tanto o homem quanto a mulher deve responder à missão a que são chamados por Deus. A necessidade de conhecer a vocação é análoga ou, de alguma forma, coincide com a tarefa do conhecimento do eu. Descobrir e criar um vínculo com a vocação significa tornarem-se reais no mundo, ou seja, realizar-se. Quando menciona o acesso das mulheres à educação, pensa na missão conjunta de mulher-homem como agentes de transformação e de mudança cultural.

No pensamento de Edith Stein, nem o feminino e nem o masculino ocupam postos de subalternidade. Novas formas de sociabilidade precisam ser forjadas diante de um sistema capitalista e hierarquizado. Uma condição primeira para a superação do papel dominante do capitalismo é oferecer máxima resistência as suas determinações sobre nossas vidas, sobre as relações que estabelecemos cotidianamente. O capitalismo usurpa nossa individualidade e nos coisifica, ou seja, nos sujeita a representações necessárias à sua sobrevivência - eleitores passivos, consumidores ávidos, empregados submissos.

A busca de uma singularidade, tão fortemente anunciada por Edith Stein, faz-se necessária em nossa cotidianidade. E reconhecermo-nos como agentes dessa 
transformação não é apenas uma tarefa de homens e mulheres, mas das diferentes formas associativas: família, comunidade, sociedade e estado. A comunidade mantém sua centralidade em todas essas formas associativas porque envolve o ser humano na sua complexa articulação, fruto de vínculos psíquicos e espirituais através dos quais se delineia propriamente uma vida ética, que desemboca no bem da pessoa e do grupo (STEIN, 1996, p. 221-222).

Para a autora, trata-se de uma relação profunda entre solidariedade e responsabilidade social. A relação sobre a qual se fundamenta o fato educativo ocorre entre pessoas dotadas de uma individualidade única e intangível que não se conflitua com a abertura para com o outro. O valor da singularidade não é negado pela autêntica abertura para o diferente. A relação com a realidade e com os outros seres humanos, com o diferente, permite-nos um conhecimento profundo de nós mesmos. O pensamento contemporâneo precisou refletir muito sobre o valor da pessoa. As tentativas de reluzí-la a uma mera participação como ser social mostraram o seu peso no advento dos genocídios do século XX.

Nessa ótica, o momento espiritual-religioso não é um simples apêndice da vida associada e da formação, mas seu eixo. Edith Stein insiste nos seus escritos sobre a necessidade de uma visão de ser humano que considere todos os fatores em jogo na sua existência, bem como suas características de solicitudo e relatio transcendentalis descritas pelos pensadores: Santo Agostinho, São Tomás de Aquino, e, sobretudo, Duns Scoto dos quais se serve para aprofundar suas análises do núcleo mais íntimo da pessoa, núcleo que define sua peculiaridade também no interno de sua espécie.

\section{Formação e missão da mulher de acordo com sua especificidade}

Para viver plenamente a própria vocação, é necessário concretizá-la e externá-la em uma missão correspondente, de acordo com as características próprias, e isso vale tanto para o homem quanto para a mulher. Independente das diferenças, a humanidade inteira faz parte de um "todo" que se realiza e se desenvolve no curso da história, mas cabe a cada um a responsabilidade pelo seu próprio desenvolvimento pessoal. Tanto o 
homem quanto a mulher podem chegar à completa realização de suas características próprias.

A formação feminina na perspectiva steiniana deve ser vista sempre na perspectiva da formação masculina, enquanto que ambas são complementares. Munida da convicção de "possibilitar à mulher uma formação que corresponda ao nível da formação intelectual ministrada aos homens", (STEIN, 1999, p. 176), insiste na implementação de políticas educativas, e participa ativamente na luta pela reforma escolástica. A autora escreve:

A natureza da mulher exige uma formação que possa levar à prática de um amor atuante. Isso requer a formação da afetividade, uma formação religiosa e uma educação feminina que ensine a compreender o ser humano e lidar com ele (STEIN, 1999, p. 126).

Vislumbra-se nos seus escritos um distanciamento de uma proposta de formação do tipo "enciclopédica" e ou determinística.

\begin{abstract}
A formação não é uma posse externa de conhecimentos e, sim, a forma que a personalidade humana assume sob a influência de múltiplas forças vindas de fora [...]. O material a ser formado é constituído de um lado pelas aptidões físicas e psíquicas com que o ser humano nasce e [por outro lado] pelo material que lhe é constantemente acrescentado de fora e que deve ser assimilado pelo organismo (STEIN, 1999, p. 137).
\end{abstract}

Edith Stein busca o fundamento teorético nas verdades da fé nas quais encontra o "fim do homem", necessitando da filosofia para penetrar intelectualmente o conteúdo da fé, esclarecê-lo e completá-lo. A educação e a formação devem conduzir para a configuração identidade pessoal. As diferenças de gênero repercutem também na formação, mas não se trata apenas de diferença sexual, é também étnica, cultural, religiosa e, de uma maneira mais globalizada, do encontro entre culturas e tradições. A abertura ao diferente não significa anular aquilo que somos, ou seja, esquecer-se das origens e da própria tradição. A cultura constitui a base sobre a qual nos confrontamos com o outro. Assim, projeta-se em Edith Stein uma educação aberta para a diversidade e para o diferente, baseada no respeito da dignidade da pessoa humana. Em seus estudos sobre a feminilidade ela não pretende impor suas ideias nem propor soluções definitivas, mas opta por aprofundar a alma feminina na sua essência, considerando sua estrutura, diferenças e características próprias, comparando-a com o modo de ser 
especificamente masculino. Sua teologia sobre a mulher está longe das polêmicas reivindicativas dos tempos modernos: ser mulher significa, para ela, "participar no plano de Deus criador e ser, no coração da humanidade, sinal e presença do "rosto materno de Deus" (STEIN, 1999). Significa, ao mesmo tempo, autopromover-se e autovalorizar-se.

\section{A vocação da mulher}

Em suas conferências enfatiza que o fundamento último do ser humano, é o próprio Deus. Ao exortar todos para que se reconstrua este fundamento, aponta para a verdadeira liberdade e dignidade da pessoa e, portanto, para a emancipação da mulher. O papel que a mulher desenvolve na sociedade e na Igreja não é apenas de colaboração, nem tão pouco de um simples serviço suplente em situações de emergência. "A mulher enquanto ser humano foi escolhida para ajudar a fundar o novo reino de Deus [...]. O sexo feminino ganha sua nobreza pelo fato de o redentor nascer de uma mãe humana, uma mulher é a porta pela qual Deus entra no gênero humano" (STEIN, 1999, p .80 e 87).

Também a missão e a Igreja serão portadoras do amor de Deus, que dá vida, na medida em que a contribuição da mulher e do homem tiverem acolhimento harmônico e forem valorizadas na sua qualidade de reflexo do amor trinitário. De fato, para Edith Stein, a primeira realidade não está em ser homem ou mulher, mas sim em ser pessoa humana. "A pessoa humana está acima de todos os valores objetivos. O ser humano total é chamado à humanidade completa" (STEIN, 1999, p. 283).

A vocação natural da mulher é ser companheira e mãe, "mas essa não pode ser a única vocação [...]. É possível identificar também na virgindade uma forma particular do ser feminino, de modo que possa ser considerada como objetivo da formação feminina" (STEIN, 1999, p. 203 e 205).

Maria, mãe de Jesus é apresentada como o protótipo da mais pura feminilidade: é a Mater-Virgo, como protótipo do tipo feminino traçado no Antigo Testamento, e, por outro lado, é a Sponsa-Christi, exemplo daquela que dedica a Deus toda sua existência, física e espiritual. A virgindadade e a maternidade são o fim indispensável para a formação de uma mulher, no sentido de que aquela que é esposa deve também saber 
cuidar do seu próprio íntimo e manifestar, também nas suas próprias obras, a maternidade espiritual.

No centro da história humana e, sobretudo, no centro da história da mulher, está Aquela em que a maternidade foi transfigurada e, ao mesmo tempo, superada como maternidade física. Tendo em Cristo a finalidade concreta, viva e pessoal de toda a formação humana, temos em Maria a finalidade de toda a formação feminina (STEIN, 1999, p. 221-222).

O pensamento de Edith Stein e, sobretudo sua experiencia vivida, traz elementos importantes para a construção de uma práxis educativa voltada para o "cuidado", ou seja, para a ética da responsabilidade no sentido de que cada um é chamado a responsabilizar-se em relação a si, com os outros e com o mundo. Além da tarefa de cuidar do próprio ser, da própria individualidade, a mulher é chamada a cuidar da humanidade como um todo, é chamada também para a maternidade sobrenatural da Igreja, colaborando na formação da juventude. Alarga, assim, os horizontes de atuação da mulher nos planos familiar, cultural, social, político e religioso.

Dirigindo-se às mulheres católicas de nível universitário da Suíça, afirma:

Somos mulheres católicas de formação universitária. Somos! Daí se deduz a primeira tarefa que consiste em cuidar de nosso ser, de nossa individualidade. Não é qualquer ser coletivo a ser concretizado, não, trata-se de desenvolver ao máximo o nosso ser mais pessoal. Nessa tarefa existe um risco, o risco do enrijecimento, do culto da personaldiade sem reflexo para fora. Por isso, a maximização da individualidade exige o máximo de auto-renúncia. [...] Renunciar a si mesmo não significa, para a mulher católica com formação universitária, despersonalizar-se para sumir no nada dos hindus ou no coletivismo dos russos, antes é entrega ao Ser (Deus), maximização da pessoa para além dela, rompimento dos grilhões da personalidade para abrir-se à amplidão do ser (ser sobre-humano de verdade) e levar de volta as funções em prol das coisas (profissão), das pessoas (liderança), das almas (apostolado). (STEIN, 1999, p. 48).

A posição de Edith Stein diante do problema da formação feminina é evidente também no seu epistolário. Reitera, na Conferência sobre "Problemas da formação feminina”, que a República de Weimar constituiu para ela o momento 
fundamental da história da Alemanha, para o reconhecimento do papel da mulher no âmbito político ${ }^{3}$.

Jurídica e politicamente, na virada do século, as mulheres eram equiparadas aos menores de idade, isto é, às crianças e aos deficientes mentais. A Constituição de 1919 trouxe o princípio de igualdade dando às mulheres plenos direitos de cidadãs. Com a outorga do direito de votar, elas se transformaram em fator político de peso. O direito de serem também votadas lhes deu a possibilidade de assumirem posições de responsabilidade na vida do Estado (STEIN, 1999, p. 168).

Em duas Cartas dos mese de novembro e de dezembro de 1918, Edith Stein relata sua breve experiência. Dirigindo-se a Roman Ingarden, escreve: “Aderi ao partido Democrático Alemão e é até possível que eu seja eleita presidente do partido" ${ }^{4}$. Mas um mês depois escreve ao mesmo Roman Ingarden: "A política tem me decepcionado. Estou completamente desprovida de instrumentos adequados: de um conhecimento aprofundado e "pele dura", [subentenda-se como coragem] $]^{5}$. Cabe ressaltar aqui que o distanciamento da política por parte de Edith Stein não significava desinteresse pelo povo alemão, pois pertence a esse, tanto quanto ao povo judeu, até o final de sua vida.

Não obstante as mudanças políticas que se orientam para a ascensão do nazismo, sua tomada de posição diante do clima político é cautelosa. Mais decisivas são suas intervenções nos planos teórico e prático, sobretudo, no que diz respeito à finalidade e à estrutura do ensino, momento central para o crescimento do povo.

Precisamos de uma preparação política e social completa para o cumprimento dos deveres civis (aliás, não só para as mulheres, e sim para todo o povo alemão que se viu lançado no sitema democrático sem que estivesse maduro para ele), além de cursos especiais de preparação para as diversas carreiras funcionais que exigem a presença do trabalho feminino. Tudo isso poderia realizar-se aos poucos, se tivéssemos diante de nós anos de

\footnotetext{
${ }^{3}$ Fazendo um comparativo com o Feminismo no Brasil, constata-se que a mulher vivia as mesmas condições. Na Constituição de 1891, as mulheres não foram sequer citadas.

4 "Ho aderito al Partito Democratico Tedesco ed è persino possibile che io sia eletta presidente del partito". (Tradução nossa). (STEIN, 2001, p. 144).

5 "La politica mi ha disgustato. Sono completamente sprovvista degli strumenti adatti: una conoscenza (Gewissen) robusta e pelle dura. (Tradução nossa). (STEIN, 2001, p. 152).
} 
desenvolvimento tranquilo. Fica difícil prever como as coisas se ajeitariam com a interrupção violenta do desenvolvimento orgânico (STEIN, 1999, p. 169).

A ruptura violenta, prevista nessa conferência, acontecerá, mas a ação de Edith Stein se desloca, agora do âmbito político e cultural àquele religioso. Seus escritos inspiraram, de certa forma, não somente a Igreja Católica, na elaboração um ensimanento sobre a mulher, no modo de entender a missão e sua posição jurídica na Igreja, mas também outras instituições educativas, com a família e o estado.

É visivel sua posição de intelectual católica diante do nazismo: sua atitude de "resistência" é testemunhada pela Carta enviada para o Papa Pio XI em que solicita uma posição da Igreja diante do antissemitismo. ${ }^{6}$ Seu forte apelo coloca-se como uma denúncia de perda e de manipulação de autênticos valores cristãos e, como luta, contra a violação dos direitos humanos, devido à distorção da fonte judaico-cristã que, historicamente, determinou a civilização ocidental. Sua posição sobre os sistemas totalitários é delineada nas suas pesquisas sobre o estado. É atenta aos sinais do seu tempo e aprofunda na sua experiência existencial também à dimensão religiosa.

Edith Stein não só procurou penetrar com sua inteligência no Mysterium Crucis, ela também experimentou o sofrimento na sua própria pessoa. João Paulo II, em 1987, na cerimônia da beatificação, descreve a forma como ela participou do destindo do seu povo, dizendo:

logo desde o momento em que começou a compreender o destino do povo de Israel 'aos pés da cruz' [...] acolheu cada vez mais intensamente Jesus Cristo no seu profundo mistério de redenção, para se sentir em unidade espiritual com os múltiplos sofrimentos da pessoa humana e para ajudar a perdoar as injustiças deste mundo, que bradam aos céus.

\footnotetext{
${ }^{6}$ Transcrevemos apenas alguns trechos da Carta de Edith Stein enviada ao Papa Pio XI, escrita em abril de 1933, para assinalar os perigos da ideologia nacional-socialista e do antissemitismo. "Santo Padre! Como filha do povo judeu, que por graça de Deus, há onze anos é filha da Igreja Católica, ouso expressar ao Pai da cristandade o que preocupa milhões de alemães. Há semanas somos expectadores, na Alemanha, de advertências que contêm um total desprezo pela justiça e pela humanidade, para não falar pelo a mor ao próximo. Há anos os chefes do nacional-socialismo tem pregado o ódio contra os hebreus. Agora que chegaram ao poder e armaram seus seguidores - dentre os quais famosos criminosos - a semente do ódio desabrocha [...]. Tudo o que aconteceu e acontece, cotidianamente, vem de um governo que se define "cristão". Não somente os hebreus, mas também milhares de fiéis católicos da Alemanha e, considero de todo o mundo, há semanas esperam e tem esperança de que a Igreja de Cristo faça ouvir sua voz contra tais abusos do nome de Cristo [...]. Todos nós, que vemos a atual situação alemã como filhos fiéis da Igreja, tememos o pior para a imagem da própria Igreja se o silêncio se prolongar indefinidamente [...]”. (ALLES BELLO; CHENAUX, 2005, p. 104105).
} 
Nela podemos encontrar maneiras para tornar possível e acreditável o anúncio do Evangelho e falar de Deus para o homem de hoje desumanizado. Três são as orientações ou práticas úteis que podemos deduzir dos seus textos pedagógicos: a eficácia do anúncio de Deus aos pobres deste mundo será proporcional à nossa capacidade de mostrarmos Seu rosto de Pai-Mãe, que se preocupa com a dignidade de cada pessoa e com os direitos de cada povo; a linguagem com que falamos de Deus torna-se compreensível quando seremos capazes de comunhão, solidariedade, diálogo e de fraternidade entre todos e, nossas referências a Deus devem estar articuladas com a pesquisa e anúncio de sinais de esperança, mesmo face às situações de dor e de morte.

Edith Stein e João Paulo II, ${ }^{7}$ com outros filósofos e teólogos, oferecem uma importante contribuição à antropologia feminina cristã. Hoje, no mundo todo soa o famoso número 22 de "Gaudium et Spes", "Cristo revela o que é o homem ao próprio homem". Esta Constituição é um dos pilares do Vaticano II e João Paulo II colaborou diretamente em sua redação. Depois, fez-lhe um profundo comentário ao longo de todo seu pontificado.

Não podemos descartar a hipótese de que João Paulo II tenha se inspirado em Edith Stein para propor um novo feminismo para a Igreja Católica Romana. Uma base fundamental para a proposta de uma antropologia feminina é colocada por João Paulo II no seu magistério, revelando com sua ação e seus escritos um grande testemunho do interesse pastoral pelas mulheres e representam uma referência para o mundo católico.

Tratando da questão feminina o Papa apresenta na Mulieris Dignitatem, o tema da reciprocidade como elemento regulador e de equilíbrio entre homem e mulher. Afirma: "Trata-se de uma relação recíproca: do homem com a mulher e da mulher para com o homem". A pessoa é considerada como um ser de relações: “o homem e a

\footnotetext{
${ }^{7}$ Karol Wojtyla nasceu no dia 18 de maio de 1920 em Wadowice, no sul da Polônia. Filho de Karol Wojtyla, um militar do exercito austro-húngaro, e Emilia Kaczorowsky, uma jovem de origem lituana. Em 1938 foi admitido na universidade de Jagieloniana, onde estudou poesia e drama. Durante a segunda Guerra Mundial (1939-1945), esteve numa mina em Zakrzowek, trabalhou na fábrica Solvay e manteve uma intensa atividade ligada ao teatro, antes de ser seminarista. Durante os anos do seminário teve de viver oculto com outros seminaristas, que foram acolhidos pelo Cardeal de Cracóvia. Ordenado sacerdote em 1946, vai completar o curso universitário no Instituto Angelicum de Roma e doutora-se em Teologia na Universidade Católica de Lublin, onde foi professor de Ética. Em 1958, foi consagrado bispo auxiliar do administrador apostólico de Cracóvia D. Baziak. Participou do Concílio Vaticano II, onde colaborou ativamente, nas comissões responsáveis na elaboração da Constituição Dogmática Lúmen Gentium e a Constituição conciliar Gaudium et Spes. Em 1964 sucedeu D. Baziak na sede de Cracóvia como Arcebispo, onde se caracterizou pela integração dos leigos nas tarefas pastorais, pela promoção do apostolado juvenil e vocacional, pela construção de Igrejas, apesar da forte oposição do regime comunista, pela promoção humana e formação religiosa dos operários e também pelo estímulo ao pensamento e publicações católicas. Representou igualmente a Polônia em cinco sínodos internacionais de bispos entre 1967 e 1977. Em maio de 1967, Wojtyla foi nomeado Cardeal pelo Papa Paulo VI e no dia 15 de outubro de 1978, Cardeal Wojtyla é eleito Papa, sucedendo João Paulo I (Albino Luciani) que após 33 dias de pontificado, faleceu. João Paulo II permanece no Pontificado 26 anos e meio (1978-2005). Ele imprimiu na Igreja um novo dinamismo, impondo ao mesmo tempo maior rigor teológico e disciplinar (GRANDES NOMES. Biografias, entrevistas, fatos de mulheres e homens que marcaram a história da Igreja. In: Doutrina Católica. Revista Quinzenal. Disponível em: dcatolica@uol.com.br. Site: http://www.doutrinacatolica.com.br/1.html. Acesso 20/01/2009.
} 
mulher, criados como uma 'unidade dos dois' na humanidade comum”, são chamados a viver uma comunhão de amor, e desse modo, a refletir no mundo a comunhão de amor do Deus uno e trino. A pessoa humana criada à imagem e semelhança de Deus, na 'unidade dos dois', é chamada não só a existir, desde o início, 'um ao lado do outro, ou juntos', mas também a existir reciprocramente, 'um para o outro'” (JOÃO PAULO II, 1988, 7). Esse tema se apresenta como uma das temáticas dominantes do Magistério de João Paulo II, o que leva a uma revisão antropológica definitiva (ALES BELLO, 2007, p. 69).

O Papa aborda a sexualidade como uma experiência de comunhão entre a mulher e o homem. Nela propõe um ensinamento rico e original sobre a sexualidade humana. Wojtyla recusa separar a "pessoa" do corpo, e afirma que o nosso espírito e o nosso corpo são feitos um para o outro, entra um no outro, interpenetram-se no segredo do nosso ser. Para o Papa, mesmo o celibato é compreendido à luz do matrimônio, o sacramento por meio do qual o criador revelou à humanidade a comunhão da sua própria natureza.

Em 1979, logo no primeiro ano do seu pontificado, João Paulo II devotou 15 minutos de cada audiência geral semanal, ao longo de cinco anos, para meditações densas e rigorosas sobre a sexualidade humana. João Paulo II não apenas reflete sobre o ser mulher, mas também propõe as mulheres como exemplos na história da Igreja. Encontramos nos escritos e no Magistério de João Paulo II, o desenvolvimento da antropologia steiniana, ambos se debruçam na busca da verdade sobre ser humano.

João Paulo II e Edith Stein partem da experiência do homem situada na própria existência para falar do ser humano. Quando falam em experiência do ser humano, entendem dizer que o ser humano se aproxima de si e com ele mesmo instaura um contato de conhecimento. Na íntima união desse contato, desenvolve-se o processo de autocompreensão que, por sua vez, compõe-se de muitas outras compreensões, assim como a experiência é composta de muitas outras experiências. A experiência do ser humano enquanto homem é individual, e às vezes, única e intransferível.

\section{Considerações finais}

Constatamos do supracitado que Edith Stein assume uma postura própria diante do feminismo ocidental do século vinte: a diferença dos movimentos que se 
empenhavam na luta pela conquista dos direitos das mulheres reflete sobre a natureza, a peculiaridade própria da mulher. Nos seus escritos, descreve a vocação e a função da mulher do ponto de vista filosófico, antropológico e teológico. Desde seu primeiro trabalho científico sobre a empatia (1916), se interessa pelo conhecimento do ser humano na sua dimensão intersubjetiva. Nos escritos sucessivos, em Psicologia $e$ ciências do espírito. Contribuição para uma fundação filosófica (1922) e, em Pesquisas sobre o Estado (1925) aprofunda a natureza humana na sua dualidade masculina e feminina e descreve de modo essencial às esferas psíquicas e espirituais, os momentos constitutivos da comunidade, as formas de vida associada, as normas que regulamentam as relações intersubjetivas, a autonomia do sujeito tanto na esfera ética individual quanto na esfera religiosa.

Com muita perspicácia, afirma, com base na tradição tomista-aristotélico, que a espécie humana é articulada "em duas espécies: espécie viril e espécie muliebre, e que a essência do ser humano, tanto num caso como no outro não deve lhe faltar nenhum traço, [esta] manifesta-se em dois modos diversos revelando a marca específica e a estrutura do ser" (STEIN, 1999, p. 2006).

A diferença entre o feminino e o masculino é abordada ao lado da unidade do ser humano: de fato, homem e mulher são seres humanos, nisso consiste sua igualdade, mas são também diferentes no sentido de que não é só o corpo ou as funções fisiológicas que são diferentes, a vida toda no corpo é diferente, a relação entre a alma e o corpo é diferente, e no âmbito da alma, difere a relação entre o espírito e a sensitividade bem como a relação entre as diversas forças espirituais.

A forma feminina e masculina não se manifesta só no ritmo constitutivo dos indivíduos, mas investe toda a estrutura de corpo, alma e espírito. Portanto, a diferença entre homem e mulher deve ser entendida como algo que atravessa toda a estrutura do ser humano como tal pela diferenciação sexual. "Em cada indivíduo, encontramos o elemento masculino e feminino, sendo que apenas um deles predomina, precisamos então das duas espécies para desenvolver a espécie humana”. A autora indica brevemente, no que consistem os momentos fundamentais da distinção entre a espécie masculina e espécie feminina: “A espécie feminina corresponde à unidade e à integridade de toda a personalidade psicofísica, o desenvolvimento harmonioso das 
forças; a espécie masculina se destaca pela potencialização máxima de forças isoladas" (STEIN, 1999, p. 187 e 206).

É nesse ponto que se constata o enxerto entre filosofia e teologia: a diferenciação da espécie proposta pela filosofia, responde à finalidade dos sexos assim como é apresentada pela teologia. É sobre essa diferença que ela se fundamenta para indicar o destino da mulher e do homem, para aprofundar o significado do feminino em relação ao masculino e, consequentemente, para abordar a questão da relação entre os dois. Nessa perspectiva, discute a vocação do homem e da mulher, não somente como um chamado ou uma profissão para (berufen), mas, sobretudo como um chamado de ordem religiosa: "Existem muitos caminhos pelos quais o chamado nos alcança: Deus mesmo o pronuncia nas palavras do Antigo e do Novo Testamento. Está inscrito na natureza do homem e da mulher" (STEIN, 1999, p. 68). Observa-se, assim, que a análise da questão do feminino e do masculino é realizada por uma multiplicidade de métodos indicados na conferência sobre Problemas da formação feminina. O texto da conferência acena ao método de análise das ciências naturais (especialmente psicológico-elementar), ao método das ciências humanas (especialmente psicológicoindividual), ao método filosófico e ao método teológico.

É somente depois de ter fixado a atenção sobre os fundamentos filosóficos e teológicos que Edith Stein desenvolve seu discurso sobre a inserção da mulher na sociedade. A atividade profissional feminina extradoméstica não é contrária à natureza e à graça, desde que não contrarie a vida doméstica, ou seja, o bem e a harmonia do núcleo familiar. Por séculos as profissões extra-domésticas foram confiadas ao homem. Essa é a luta do movimento feminino que, nos tempos de Edith Stein, reclamava a admissão das mulheres às diferentes profissões e que, na Alemanha, estavam tomando forma. Particularmente sugestivas, são as páginas escritas pela autora sobre a mulher, embora a linguagem utilizada reflita o contexto de sua época:

A alma da mulher precisa ser ampla e aberta a tudo o que é humano; ela precisa ser cheia de paz, para que as pequenas chamas não sejam apagadas por vendavais; ela precisa ser quente, para que as sementinhas frágeis não se congelem; ela precisa ser clara, para que as ervas daninhas não possam alojarse em cantos e dobras escuros; reservada, para que os assaltos de fora não ponham em perigo a vida em seu interior; vazia de si, para que a outra vida tenha lugar nela; e, finalmente, senhora de si e de seu corpo, para que toda a sua personalidade esteja preparada para atender qualquer chamado (STEIN, 1999, p. 140). 
É com essa bagagem filosófico-cultural, unida a sua experiência didática e de contato com os problemas sociais e políticos, que Edith Stein examina a questão feminina, com uma completude que representa, talvez, um exemplo, como afirma Angela Ales Bello, "único na história da antropologia cristã sobre a mulher" (ALES BELLO, 2009, p. 69).

Referenciais

ALES BELLO, Angela. Edith Stein. La passione per la verità. Messaggero di Sant'Antonio. Editrice: Padova, 2003.

ALES BELLO, ANGELA; PEZZELLA, Ana Maria. Il femminile tra oriente e ocidente. Religione literatura cultura storia. Roma: Città Nuova Editrice, 2005.

ALES BELLO, Angela; CHENAUX, Philippe. Edith Stein e o nazismo. Roma: Città Nuova, 2005.

ALES BELLO. Angela. Differenza sessuale e domanda antropológica. In: RICHI, Alberti, (a cura di). Al cuore dell'umano. La domanda antropologica 1. Roma: Marcianum Press, 2007

ALES BELLO, Angela. Edith Stein O dell'armonia. Esistenza, Pensiero, Fede. Roma: Edizioni Studium-Roma, 2009.

GELBER, L. Prefácio dos Editores. In: STEIN, Edith. A mulher: sua missão segundo a natureza e a graça. Bauru, SP: EDUSC, 1999. Tradução de: "Die Frau, ihre Aufgabe nach Natur und Gnade". "Edith Steins Werke“, vol. V, edite a cura di L. Gelber; P. Romaeus Leuven. Nauwelaerts, Lovanio 1959. Tradução Alfred J. Keller.

GRANDES NOMES. Biografias, entrevistas, fatos de mulheres e homens que marcaram a história da Igreja. In: Doutrina Católica. Revista Quinzenal. Disponível em:dcatolica@uol.com.br. Site: http://www.doutrinacatolica.com.br/1.html. Acesso 20/01/2009.

JOÃO PAULO II. Carta Apostólica de João Paulo II. Mulieris Dignitatem, A Dignidade da mulher. 15/08/1988, 6. ed. São Paulo, SP: Paulinas, 2005. (Documentos pontifícios, 118).

PERROT, Michelle. Minha história das mulheres. São Paulo: Contexto, 2007.

PEZZELLA, Ana Maria. L'Antropologia filosofica di Edith Stein. Indagine fenomenologica della persona humana. Prefazione di Angela Ales Bello. Roma: Città Nuova Editrice, 2003. 
STEIN, Edith. A mulher: sua missão segundo a natureza e a graça. Bauru, SP: EDUSC, 1999. Tradução de: "Die Frau, ihre Aufgabe nach Natur und Gnade". "Edith Steins Werke“, vol. V, edite a cura di L. Gelber; P. Romaeus Leuven. Nauwelaerts, Lovanio 1959. Tradução Alfred J. Keller.

STEIN, Edith. A vida cristã da mulher. In: STEIN, Edith. A mulher: sua missão segundo a natureza e a graça. Bauru, SP: EDUSC, 1999. Tradução de: "Die Frau, ihre Aufgabe nach Natur und Gnade". "Edith Steins Werke", vol. V, edite a cura di L. Gelber; P. Romaeus Leuven. Nauwelaerts, Lovanio 1959. Tradução Alfred J. Keller.

STEIN, Edith. A vocação do homem e da mulher de acordo com a ordem natural e da graça. In: STEIN, Edith. A mulher: sua missão segundo a natureza e a graça. Bauru, SP: EDUSC, 1999. Tradução de: "Die Frau, ihre Aufgabe nach Natur und Gnade". "Edith Steins Werke“, vol. V, edite a cura di L. Gelber; P. Romaeus Leuven. Nauwelaerts, Lovanio 1959. Tradução Alfred J. Keller.

STEIN, Edith. As bases da formação feminina. In: STEIN, Edith. A mulher: sua missão segundo a natureza e a graça. Bauru, SP: EDUSC, 1999. Tradução de: "Die Frau, ihre Aufgabe nach Natur und Gnade". "Edith Steins Werke", vol. V, edite a cura di L. Gelber; P. Romaeus Leuven. Nauwelaerts, Lovanio 1959. Tradução Alfred J. Keller.

STEIN, Edith. Edith Stein. Lettere a Roman Ingarden 1917-1938. Città del Vaticano: Libreria Editrice Vaticana, 2001.. Presentazione di Angela Ales Bello. Titolo originale. Briefe an Roman Ingarden 1917-1938. In: "Edith Steins Werke", vol. XIV (a cura di L. Gelber e M. Linssen), O. C.D, 1991, Verlag Herder, Freiburg i. Br. Traduzione di Elio Constantini ed Erika Schulze Constantini. Revisione e integrazione Anna Maria Pezzella.

STEIN, Edith. Ethos das profissões femininas. In: STEIN, Edith. A mulher: sua missão segundo a natureza e a graça. Bauru, SP: EDUSC, 1999. Tradução de: "Die Frau, ihre Aufgabe nach Natur und Gnade". "Edith Steins Werke", vol. V, edite a cura di L. Gelber; P. Romaeus Leuven. Nauwelaerts, Lovanio 1959. Tradução Alfred J. Keller.

STEIN, Edith. Problemas da formação feminina. In: STEIN, Edith. A mulher: sua missão segundo a natureza e a graça. Bauru, SP: EDUSC, 1999. Tradução de: "Die Frau, ihre Aufgabe nach Natur und Gnade". "Edith Steins Werke", vol. V, edite a cura di L. Gelber; P. Romaeus Leuven. Nauwelaerts, Lovanio 1959. Tradução Alfred J. Keller.

STEIN, Edith. Edith Stein. Lettere a Roman Ingarden 1917-1938. Città del Vaticano: Libreria Editrice Vaticana, 2001. Presentazione di Angela Ales Bello. Titolo originale. Briefe an Roman Ingarden 1917-1938. In: "Edith Steins Werke", vol. XIV (a cura di L. Gelber e M. Linssen), O. C.D, 1991, Verlag Herder, Freiburg i. Br. Traduzione di Elio Constantini ed Erika Schulze Constantini. Revisione e integrazione Anna Maria Pezzella. 
Recebido: 21/09/2013

Received: 0921/2013

Aprovado: 19/12/2013

Approved: 12/19/2013 